\title{
Maternal mortality at a tertiary health care: a retrospective study
}

\author{
Sona Singh, Nagendra Singh*, Jagriti Kiran Nagar, Sarvesh Jain
}

Department of Obstetrics and Gynecology, Bundlekhand Medical College, Sagar, Madhya Pradesh, India

Received: 08 April 2018

Accepted: 10 April 2018

\section{*Correspondence:}

Dr. Nagendra Singh,

E-mail: drnagendra.804@gmail.com

Copyright: (c) the author(s), publisher and licensee Medip Academy. This is an open-access article distributed under the terms of the Creative Commons Attribution Non-Commercial License, which permits unrestricted non-commercial use, distribution, and reproduction in any medium, provided the original work is properly cited.

\section{ABSTRACT}

Background: Maternal mortality is the death of a woman while pregnant or within 42 days of termination of pregnancy irrespective of the duration and site of pregnancy from any cause related to or aggravated by the pregnancy, but not from accidental or incidental causes. The aim of this study is to find out the causes of maternal mortality and the complications leading to maternal death.

Methods: A retrospective study was conducted by reviewing the hospital records to study the maternal deaths and complication leading to maternal death over the period of one year from July 2016 June 2017 in the Department of Obstetrics and Gynecology, Bundelkhand Medical College, and associated hospital Sagar, Madhya Pradesh. All the maternal deaths were scrutinized for various aspects likely to be related to death such as age, locality of residence, antenatal care, admission death interval and the cause of death.

Results: The maternal mortality ratio in the present study is $292.33 / 100,000$ live births. There were 28 maternal deaths out of 9578 live birth during the study period. The majority of deaths occurred in the 20-30 age group. hemorrhage (32.14\%) and hypertensive disorders (14.28\%) are two most common direct cause of maternal deaths. $42.85 \%$ of maternal deaths occurred within the first twenty-four hours of admission. Post-operative and post abortal sepsis, amniotic fluid embolism and pulmonary embolism are other direct causes. Indirect causes of maternal deaths account for $21.42 \%$. Severe anemia was the leading indirect causes of maternal deaths.

Conclusions: Hemorrhage, hypertensive disorders, and anaemia remain the major cause of maternal deaths. Delay in decision making, provision of treatment and referral to tertiary centre contributed higher maternal mortality. This requires more efforts to recognize the direct and indirect causes of maternal deaths.

Keywords: Anaemia, Hemorrhage, Hypertensive disorders, Maternal death

\section{INTRODUCTION}

Maternal mortality is the death of a woman while pregnant or within 42 days of termination of pregnancy irrespective of the duration and site of pregnancy from any cause related to or aggravated by the pregnancy, but not from accidental or incidental causes. ${ }^{1}$

The index of the quality of health care delivery system of a country is reflected by its maternal mortality rate (MMR). Along with $16 \%$ of the world's population, India accounts for over $20 \%$ of the world's maternal deaths. Every minute every day, a woman dies as a result of pregnancy and childbirth somewhere in the world. Every year, approximately 600,000 women die of pregnancyrelated causes, and $98 \%$ of these deaths occur in developing countries. $^{2}$

In India approximately 28 million women experience pregnancy and 26 million have live births. An estimated 67000 maternal deaths and 1 million newborn deaths occur each year. India has observed appreciable decline 
in MMR from 677 in 1980 to 254 in 2005-06 and to 212 in 2007-09. National Rural Health Mission and Millennium Development Goals (MDG5) sets target to reduce MMR to less than 100 by $2015 .^{3}$

About $80 \%$ of maternal mortality are mainly due to theses five complications includes: hemorrhage, sepsis, pregnancy-induced hypertension, rupture uterus (obstructed labor), and complication of abortion. Hemorrhage is a major cause for maternal mortality because, once bleeding starts, death can occur in around 2 hours compared with 10 hours for eclampsia and 72 hours for obstructed labour. ${ }^{4} \mathrm{WHO}$ has reported maternal mortality rate for India in 2015 at 174 per 100,000 live births. MMR in India is declining faster than global target and the aim of government is to bring it down to 100 by $2020 . .^{5}$ In India, there is lotoff variation in MMR and healthcare access between regions and in socioeconomic factors. ${ }^{6,7}$ The tragedy is that these deaths are preventable. Pregnancy is not a disease and pregnancy related mortality is almost always preventable.

Regular care of a pregnant woman plays an important role in prevention and early recognition of complications leading to maternal death. ${ }^{8}$ Prevention of maternal deaths remains one of the most important objectives of the National Family Welfare Program. ${ }^{9}$ The aim of this study was to analyze the MMR in the tertiary care center and find out the various causes leading to maternal deaths.

\section{METHODS}

This is a retrospective study conducted by reviewing the hospital records of maternal deaths over the period of one year from July 2016 to June 2017 in the Department of Obstetrics and Gynecology, Bundelkhand Medical College, and associated hospital Sagar.

All maternal deaths that occurred in the hospital ware scrutinized for various aspects likely to be related to death such as age, locality of residence, antenatal care, admission death interval and the cause of death and the data was analyzed to study the cause and complications leading to maternal deaths. A total of 28 cases were obtained from the patients' files of the maternal deaths from medical records.

\section{Inclusion criteria}

- Maternal deaths that occurred within the period of pregnancy

- Maternal deaths that occurred within 42 days postpartum

\section{Exclusion criteria}

- Maternal deaths that occurred due to accidental or incidental causes
- Maternal death with incomplete information on the files and clinical notes

The data of maternal deaths obtained from the tertiary care centre analyzed under following points

- Maternal mortality ratio in the tertiary care centre in study period scrutinized from the medical records of the concerned department

- Maternal deaths and its characteristics according to age, antenatal care, locality and parity

- Maternal deaths in relation to referral from other places

- Time interval between maternal admission and death

- Maternal deaths in relation to the route of delivery

- Status of the mother at the time of death

- Direct causes of maternal mortality

- Indirect causes of maternal mortality.

- Analysis of maternal mortality and its causes done.

\section{RESULTS}

During the study period there were 28 maternal deaths out of 9783 deliveries and 9578 live birth giving an MMR of 292.33 per 1 lakh live birth (Table 1).

Table 1: Maternal mortality ratio in the tertiary centre from July 2016 to June 2017.

\begin{tabular}{|llll|}
\hline $\begin{array}{l}\text { Total no. } \\
\text { of delivery }\end{array}$ & $\begin{array}{l}\text { Total no. } \\
\text { of live } \\
\text { births }\end{array}$ & $\begin{array}{l}\text { Total no. of } \\
\text { maternal } \\
\text { deaths }\end{array}$ & $\begin{array}{l}\text { Maternal } \\
\text { mortality } \\
\text { ratio }\end{array}$ \\
\hline 9783 & 9578 & 28 & $\begin{array}{l}292.33 \% \text { per } \\
1 \text { lakh live } \\
\text { births }\end{array}$ \\
\hline
\end{tabular}

The data of maternal deaths obtained from the tertiary care centre have been tabulated as follows.

Table 2: Maternal deaths and its characteristics according to age, antenatal care, locality and parity

$$
(\mathbf{n}=28) \text {. }
$$

\begin{tabular}{|c|c|c|c|}
\hline & Group & $\begin{array}{l}\text { Maternal } \\
\text { deaths }\end{array}$ & Percentage \\
\hline \multirow{3}{*}{$\begin{array}{l}\text { Age } \\
\text { (years) }\end{array}$} & $<20$ & 3 & 10.71 \\
\hline & $20-30$ & 21 & 75 \\
\hline & $>30$ & 4 & 14.28 \\
\hline \multirow{2}{*}{ Parity } & Primigravida & 11 & 39.28 \\
\hline & Multigravida & 17 & 60.71 \\
\hline \multirow{2}{*}{$\begin{array}{l}\text { Antenatal } \\
\text { care }\end{array}$} & Booked & 3 & 10.71 \\
\hline & Unbooked & 25 & 89.28 \\
\hline \multirow{2}{*}{ Locality } & Rural & 24 & 85.71 \\
\hline & Urban & 4 & 14.28 \\
\hline
\end{tabular}

As shown in Table 2, out of the 28 deaths, $21(75 \%)$ were in the $20-30$ age group. $4(14.28 \%)$ were more than 30 age group and $3(10.71 \%)$ were below 20 years of age. 17 $(60.71 \%)$ women were multigravida and $11(39.28 \%)$ 
were Primigravida. Maximum deaths 25 (89.28\%) have occurred which were unbooked and only $3(10.71 \%)$ cases were booked. $24(85.71 \%)$ women deaths were belonging to rural areas and $4(14.28 \%)$ were from urban areas.

Table 3: Maternal deaths in relation to referral from other places.

\begin{tabular}{|lll|}
\hline Referral hospital & $\begin{array}{l}\text { No. of cases referred } \\
(\mathrm{n}=28)\end{array}$ & $\%$ \\
\hline Primary health centre & 16 & 57.14 \\
\hline $\begin{array}{l}\text { Community health } \\
\text { centre }\end{array}$ & 9 & 32.14 \\
\hline Directly from home & 3 & 10.71 \\
\hline
\end{tabular}

As seen from Table 3, 16 (57.14\%) women were referred from primary health centre whereas $9(32.14 \%)$ were from community health centre and only 3 (10.71\%) women came directly from home.

Table 4: Time interval between maternal admission and death.

\begin{tabular}{|lll|}
\hline Time interval & No. of cases & Percentage \\
\hline $0-24$ hours & 12 & 42.85 \\
\hline $24-48$ hours & 8 & 28.57 \\
\hline $48-72$ hours & 5 & 17.85 \\
\hline$>72$ hours & 3 & 10.71 \\
\hline
\end{tabular}

In Table 4, Maximum deaths $12(42.85 \%)$ had occurred within the first 24 hours of admission. 8 (28.57\%) died within 24-48 hrs 5 (17.85\%) died within 48-72 hrs and 3 $(10.71 \%)$ died after 72 hrs.

Table 5: Maternal deaths in relation to the route of delivery.

\begin{tabular}{|lll|}
\hline Route of delivery & No. of cases & Percentage \\
\hline Vaginal delivery & 20 & 71.42 \\
\hline LSCS delivery & 3 & 10.71 \\
\hline Not delivered & 5 & 17.85 \\
\hline
\end{tabular}

Table 5, shows the modes of delivery conducted out of which $20(71.42 \%)$ women who died prior to vaginal delivery and $3(10.71 \%)$ women had LSCS prior to death and $5(17.85 \%)$ women died undelivered.

Table 6: Status of the mother at the time of death $(\mathrm{n}=28)$.

\begin{tabular}{|lll|}
\hline Status of mother & No. of cases & Percentage \\
\hline Post abortal & 1 & 3.57 \\
\hline Ante partum & 6 & 21.42 \\
\hline Intra partum & 2 & 7.14 \\
\hline Post-partum & 19 & 67.85 \\
\hline
\end{tabular}

The above Table 6 , shows most of the women had died during postpartum period which accounts for $19(67.85 \%)$ and $6(21.42 \%)$ women died during ante partum period. 2 $(7.14 \%)$ women died during intra partum period and only $1(3.57 \%)$ women died post abortal.

Table 7: Direct causes of maternal mortality (Total no. of maternal deaths $n=28$ ).

\begin{tabular}{|lll|}
\hline Cause of Death & No. of cases & Percentage \\
\hline Postpartum hemorrhage & 9 & 32.14 \\
\hline Ante partum hemorrhage & 3 & 10.71 \\
\hline $\begin{array}{l}\text { Pregnancy induced } \\
\text { hypertension/HELLP }\end{array}$ & 4 & 14.28 \\
\hline DIC & 1 & 3.57 \\
\hline $\begin{array}{l}\text { Obstructed labour with } \\
\text { rupture uterus }\end{array}$ & 1 & 3.57 \\
\hline $\begin{array}{l}\text { Post-operative LSCS } \\
\text { with sepsis }\end{array}$ & 1 & 3.57 \\
\hline Post abortal sepsis & 1 & 3.57 \\
\hline Pulmonary embolism & 1 & 3.57 \\
\hline Amniotic fluid embolism & 1 & 3.57 \\
\hline Total & 22 & 78.57 \\
\hline
\end{tabular}

Most common direct causes of maternal death are hemorrhage (PPH) 9 (32.14\%) and hypertensive disorders which includes eclampsia and HELLP syndrome related deaths which accounts for 4 (14.28\%). Ante partum hemorrhage constitutes $3(10.71 \%)$ and the rest DIC, obstructed labour with rupture uterus, postoperative LSCS with sepsis, post abortal sepsis, pulmonary embolism and amniotic embolism each account for $1(3.57 \%)$.

Table 8: Indirect causes of maternal mortality.

\begin{tabular}{|lll|}
\hline $\begin{array}{l}\text { Cause of } \\
\text { maternal death }\end{array}$ & $\begin{array}{l}\text { No. of } \\
\text { deaths }\end{array}$ & Percentage \\
\hline $\begin{array}{l}\text { Severe anemia } \\
\text { Hepatitis }\end{array}$ & 3 & 10.71 \\
\hline Pneumonia with ARDS & 1 & 3.57 \\
\hline $\begin{array}{l}\text { Blood transfusion reaction } \\
\text { with ARF }\end{array}$ & 1 & 3.57 \\
\hline Total & 6 & 3.57 \\
\hline
\end{tabular}

Severe anemia constitutes the most common indirect cause of maternal deaths than followed by hepatitis, pneumonia with ARDS and blood transfusion reaction with ARF.

\section{DISCUSSION}

Death of mother is a catastrophic event and it has a significant impact on the family, society and country. Maternal death indicates the quality of maternal services provided to women in the society. A high rate of MMR manifests poor antenatal care, late referral, illiteracy and low socioeconomic status. The objective of MDG-5 is to reduce the maternal mortality especially in low income countries where 1 in 16 women die of pregnancy related complications. ${ }^{10}$ The maternal mortality in the present 
retrospective study was found to be $292.33 / 1,00,000$ live birth which is comparable to studies done by Pathak et al who had reported MMR of 428-869.6/100,000 live birth due to large number of referral cases. ${ }^{11}$ In the present study most of the deaths $75 \%$ occurred in 20-30 age groups which are similar to the studies that reports maximum deaths occurred in 21-30 years age group. ${ }^{12}$ In our study $60.71 \%$ of maternal deaths among multigravida and unbooked women which were accounts for $89.28 \%$ and higher number of deaths occurred in women were belongs to rural areas accounts for $85.71 \%$. All our findings are similar to that reported by Rai L et al. ${ }^{13}$

In the present study, $42.85 \%$ of deaths have occurred within the first 24 hours of admission to the hospital. Postpartum deaths accounted for approximate 67-85\% and this is comparable with study done by Khumathem PD et al, who reported that postpartum deaths accounts for $70 \%$ of maternal deaths. ${ }^{14}$ Patients referred from primary health centre and community health centre accounts for $89.28 \%$. Most of them had referred after the onset of complications. In this study most of the referral centres are failed to provide critical care management that those referred patients were needed. Early diagnosis and timely referral of high risk patients, adequate antenatal visits can prevent maternal mortality.

In this retrospective study, we found the direct causes of maternal deaths are the important risk factor for the maternal mortality which accounts for $78.57 \%$. Haemorrhage (PPH/APH) was the major cause of death which constitutes $42.85 \%$ and it is consistent with other studies done by Konar et al. ${ }^{15}$ Early identification of risk factor responsible for hemorrhage should be identified and properly managed. Hypertensive disorders were another risk factor which accounted for $14.28 \%$ of maternal death which is comparable with most of the other studies. ${ }^{12,16}$ All the severe pre-eclampsia patients should be given anticonvulsant treatment with magnesium sulfate by which the incidence of eclampsia can be reduced. Post-operative sepsis and post abortal sepsis constitutes about $7.14 \%$. Most of the deaths due to puerperal sepsis could have been saved if quality hygiene is practiced and infection needs to be recognized early and treated promptly. To avoid septic abortion related maternal deaths, all abortion services delivered by qualified medical personnel. ${ }^{17}$ Amniotic fluid and pulmonary embolism were accounts $3.57 \%$ each. In the present study, we found hepatitis is responsible for $3.57 \%$ of maternal death and $4.16-10.8 \%$ deaths have been reported in other studies. ${ }^{12}$

In this study, we found that indirect causes of maternal death accounted for $21.42 \%$ out of which anaemia constitute $(10.71 \%)$ as a major comorbid factor. Preexisting anaemia may increase as the pregnancy advances which leads to heart failure and death. Anaemia also hampers the ability of mother to resist infection or cope with hemorrhage. ${ }^{17}$ Prevention of pregnancy related anaemia by iron supplementation will be helpful in preventing maternal deaths due to severe anaemia. Emergency transport in case of need and blood transfusion facility play an important role in prevention of maternal deaths. Emergency obstetric care services and trained medical personal needs to be emphasized at community health centres and primary health centres.

\section{CONCLUSION}

Most of maternal deaths are preventable which are still high in comparison to developed countries. Reduction in maternal mortality will only be possible if high-quality obstetric service care made available to all women through ASHA workers, skilled birth attendants and referral hospital care and accountability of health providers. Obstetric hemorrhage, hypertensive disorders, medical disorders in pregnancy like severe anaemia, hepatitis can be prevented if antenatal women with high risk factor motivated to attend a tertiary care centre at an early date for early diagnosis, admission and management. The ministry of health and family welfare launched 'Laqshya' program aimed to improve quality of maternity care in labour room and maternity operation theatre. If it is being implemented to 'fast-track' intervention at all health care levels can reduce the complication of high risk pregnancies.

Funding: No funding sources Conflict of interest: None declared

Ethical approval: The study was approved by the Institutional Ethics Committee

\section{REFERENCES}

1. Abouzahr C, Wardlow T. Maternal mortality in 2000: estimates developed by WHO, UNICEF, UNFPA. WHO, Geneva, Switzerland. 2003. Available http://apps.who.int/iris/bitstream/handle/10665/6838 2/a81531.pdf;jsessionid=E01323B9B021728B0C383 B71DB83DAF5? sequence $=1$

2. Rao KA. Presidential address. The $44^{\text {th }}$ All India Obstetric and Gynaecological Congress, Ahmedabad. December 27, 2000. J Obstet Gynaecol India. 2001;51:25-8.

3. National Rural Health Mission: Framework for implementation 2005-2012; New Delhi: Ministry of Health and Family Welfare, Government of India. Available at http://www.nipccdearchive.wcd.nic.in/sites/default/files/PDF/NRHM\% 20-\%20Framework\%20for\%20Implementation\%20$\% 20 \% 202005-\mathrm{MOHFW} . \mathrm{pdf}$

4. ACOG. ACOG Committee Opinion. Number 283, May 2003. New U. S. Food and drug administration labeling on cytotec (misoprostol) use and pregnancy. Obstet Gynecol. 2003;101:1049-50.

5. India's Maternal Mortality Rate on a decline; may 27, 2017. Available at https://www.hindustantimes.com/health/india-s- 
maternal-mortality-rate-on-a-decline/story-

ZcnBG0kidtvPEkRnKNIOII.html

6. IIPS. District level household and facility survey (DLHS-3) 2007-2008: India. Mumbai: International Institute for Population Sciences. Ministry of Health and Family Welfare Government of India. 2010. Available

at http://rchiips.org/pdf/INDIA_REPORT_DLHS-3.pdf

7. Barros AJD, Ronsmans C, Axelson H, Loaiza E, Bertoldi AD. Equity in maternal, newborn, and child health interventions in countdown to 2015: a retrospective review of survey data from 54 countries. Lancet. 2012;379:1225-33.

8. Campbell OMR, Graham WJ. Strategies for reducing maternal mortality: getting on with what works. Lancet. 2006;368:1284-99.

9. Jagdish JA, Govind RP. Maternal mortality: changing trends. J Obstet Gynecol. 2007;57:398-400.

10. Puri A, Yadav I, Jain N. Maternal Mortality in an urban tertiary care hospital of North India. J Obstet Gynae India. 2011;61:280-5.

11. Pathak D, Chakraborty B, Goswami S, Adhikari S. Changing trends of maternal mortality: a comparative study. J Obstet Gynaecol India. 2011;61(2):161-5.
12. Ashok V, Santosh M, Anupa S. A study on maternal mortality. J Obstet Gynecol. 2008;58:226-9.

13. Mundkur A, Rai L. Prepare and prevent rather than repair and repent, study of maternal mortality in tertiary care hospital. Int $\mathrm{J}$ Med Public Health. 2013;3:163-6.

14. Khumanthem PD, Chanam MS, Samjetshabam RD. Maternal mortality and it's causes in a tertairy centre. J Obstet Gynecol India. 2012;62(2):168-71.

15. Konar H, Chakraborthy AB. Maternal mortality: a FOGSI study (based on institutional data). J Obstet Gynecol India. 2013;63(2):88-95.

16. Abha A, Arvind P, Bhattacharya BN. Risk factors for maternal mortality in Delhi slums: a communitybased case control study. Indian J Med Sci. 2007;61:517-26.

17. Bedi N, Kambo I, Dhillon BS. Maternal deaths in India: preventable tragedies, (an ICMR task force study). J Obstet Gynecol India. 2001;51:86-92.

Cite this article as: Singh S, Singh N, Nagar JK, Jain S. Maternal mortality at a tertiary health care: a retrospective study. Int J Reprod Contracept Obstet Gynecol 2018;7:1773-7. 